Article

\title{
Microstructure and Texture Evolution during Twin-Roll Casting and Annealing of a Mg-6.8Y2.5Zn-0.4Zr Alloy (WZ73)
}

\author{
Kristina Kittner, Madlen Ullmann *, Falko Arndt, Rudolf Kawalla and Ulrich Prahl@ \\ Institute of Metal Forming, Technische Universität Bergakademie Freiberg, Bernhard-von-Cotta Straße 4, \\ 09599 Freiberg, Germany; Kristina.Kittner@imf.tu-freiberg.de (K.K.); Falko.Arndt@imf.tu-freiberg.de (F.A.); \\ Rudolf.Kawalla@imf.tu-freiberg.de (R.K.); Ulrich.Prahl@imf.tu-freiberg.de (U.P.) \\ * Correspondence: Madlen.Ullmann@imf.tu-freiberg.de
}

Received: 8 May 2020; Accepted: 15 June 2020; Published: 16 June 2020

\begin{abstract}
In the present work, the microstructure and texture of a $\mathrm{Mg}-6.8 \mathrm{Y}-2.5 \mathrm{Zn}-0.4 \mathrm{Zr}$ sheet manufactured by twin-roll casting were investigated. The twin-roll cast state consisted of two apparent phases: the $\alpha-\mathrm{Mg}$ matrix, which was made up of dobulites with an average grain size of approximately $50 \mu \mathrm{m}$ and the LPSO (long-period stacking ordered) phase, which formed network-like precipitates along the grain boundaries. After twin-roll casting, annealing was carried out under conditions of different temperatures ranging from $450{ }^{\circ} \mathrm{C}$ to $525^{\circ} \mathrm{C}$ and holding times between $2 \mathrm{~h}$ and $24 \mathrm{~h}$. It was found that heat treatment led to the formation of a microstructure in which grains were apparent. Furthermore, it could be observed that high temperatures $>500{ }^{\circ} \mathrm{C}$ led to changes in the morphology of the LPSO structures. On one hand, the network-like structure dissolved while, on the other hand, both rodlike and blocky LPSO phases precipitated predominantly at the grain boundaries of the $\alpha-\mathrm{Mg}$ matrix. This process was fostered by high temperatures and long holding times.
\end{abstract}

Keywords: twin-roll casting; WZ73; LPSO; texture

\section{Introduction}

Magnesium alloys are often associated with low strength and insufficient ductility. However, research efforts in the development of new magnesium alloys have shown that by adding rare earth elements, alloys with excellent mechanical properties can be obtained [1]. In some alloying systems—such as Mg-Y-Zn—so-called LPSO (long period stacking ordered) structures occur which contribute significantly to improving the strength and ductility of these alloys [2,3]. LPSO structures exhibit a stacking sequence, which increases 10-, 14-, 18- or 24-fold along the c-axis [4]. Their formation has already been reported for different conditions and mainly for conventionally cast, heat treated and/or hot deformed samples [5-9]. In a $\mathrm{Mg}_{97} \mathrm{Zn}_{1} \mathrm{Y}_{2}$ alloy, for example, an 18R structure is the most common LPSO phase [10]. Furthermore, it is shown that within this stacking sequence, atomic layers are enriched with $\mathrm{Y}$ and $\mathrm{Zn}$ atoms and are arranged alternately with two $\alpha$-Mg atomic layers [11]. These lamellar structures are composed of several fine platelet-like LPSO phases arranged in parallel.

Heat treatment in the temperature range between $350{ }^{\circ} \mathrm{C}$ and $500{ }^{\circ} \mathrm{C}$ results in the transformation of the $18 \mathrm{R}$ phase into the $14 \mathrm{H}$ phase. In $\mathrm{Mg}-\mathrm{Y}-\mathrm{Zn}$ alloys, the $14 \mathrm{H}$ phase occurs in lamellar or platelet-like form either along the grain boundaries or within the grains. The occurrence of the $14 \mathrm{H}$ phase after heat treatment is observed not only in the $\mathrm{Mg}-\mathrm{Y}-\mathrm{Zn}$ alloy system, but also in $\mathrm{Mg}-\mathrm{Gd}-\mathrm{Zn}, \mathrm{Mg}-\mathrm{Gd}-\mathrm{Y}-\mathrm{Zn}$ and $\mathrm{Mg}-\mathrm{Dy}-\mathrm{Zn}$ alloys, among others [11,12].

The excellent mechanical property profile of $\mathrm{Mg}-\mathrm{Y}-\mathrm{Zn}$ alloys is attributed to the strength-enhancing effect of LPSO phases. The deformation mechanisms responsible for the improvement in strength 
and ductility compared to pure magnesium have not yet been fully understood and are currently the subject of some dispute in the literature. However, it is evident that the acting deformation mechanisms of the LPSO phase differ from those of the magnesium matrix. In their investigations on a cold-rolled $\mathrm{Mg}_{97} \mathrm{Y}_{2} \mathrm{Zn}_{1}$ alloy, Kim et al. [13] show which deformation mechanisms are dominant in the individual structural constituents. The microstructure of the alloy is composed of the $\alpha-\mathrm{Mg}$ matrix and an interdendritic LPSO phase which, as a result of cold forming, exhibit kink bands with angles between $30^{\circ}$ and $60^{\circ}$. Hagihara et al. [5], Itoi et al. [14] and Shao et al. [2] describe the formation of kink bands in magnesium alloys in which LPSO phases are formed. Kinking is fundamentally different from other deformation mechanisms, such as sliding or twin formation. One difference to sliding lies, for example, in the formation of dislocations: Sliding requires a large number of dislocations in the same slip plane, while kinking requires dislocation pairs in several parallel slip planes. Frank et al. [15] consider kink bands as areas between two approximately parallel walls, which are formed by edge dislocations with opposite signs. Starting points for kink bands are areas with increased local stress levels, such as pores or inclusions [15].

Another explanation for these superior mechanical properties is that a $\mathrm{Mg}-\mathrm{Y}-\mathrm{Zn}$ alloy with an LPSO phase is generally regarded as a two-phase material consisting of hard LPSO plates embedded in a soft Mg matrix. As can be seen from the work of Ashby et al. [16], dislocations are formed preferentially at free surfaces, grain boundaries or interfaces, such as those between matrix and particle or between matrix and embedded LPSO phase. In this case, the improvement in ductility results from the increased activation of non-basal sliding systems. As already mentioned, $\mathrm{Mg}-\mathrm{Y}-\mathrm{Zn}$ alloys are mainly produced in conventional casting processes- for example in gravity die casting. In the as-cast state, the microstructure consists of the dendritic Mg matrix and LPSO phases, which predominantly precipitate at the boundaries of the casting cells. In addition, there is precipitation of fine lamellae within the casting cells, which are usually identified as 14H-phase material [17-20]. Furthermore, the transformation from $18 \mathrm{R}$ to $14 \mathrm{H}$ during heat treatment is reported as a diffusional-displacive transformation, which is regulated by the diffusion rate of the $\mathrm{Y}$ and $\mathrm{Zn}$ atoms into the individual layers of the stacking faults [21].

Available literature on Y-containing-Mg-wrought alloys with LPSO phase typically is using extrusion as deformation process. However, twin-roll casting offering much more effective production process for wrought alloys, is rarely under investigation for LPSO containing Mg alloy [22,23]. Twin-roll casting (TRC) enables the large-scale production of sheets of magnesium alloys in a cost- and energy-efficient manner. Further advantages are a refined microstructure with reduced segregation and improved mechanical properties after further processing by strip rolling [24-26]. The combination of TRC, heat treatment and hot rolling processes facilitate specific control of the precipitation kinetics as well as the size and morphology of precipitates.

Twin-roll casting of LPSO-containing magnesium alloys has only been reported by Suzawa et al. [10], where a master alloy sheet of $\mathrm{Mg}_{97} \mathrm{Zn}_{1} \mathrm{Y}_{2}$ prepared by TRC was used. This sheet was machined into chips and subsequently extruded in order to investigate the material's superplastic behavior. However, no details of the twin-roll casting process were provided by the authors. Kim et al. [7] investigate the mechanical properties and microstructure of a $\mathrm{Mg}_{97.3} \mathrm{Zn}_{2.3} \mathrm{Y}_{0.4}$ magnesium alloy after twin-roll casting. According to the $\mathrm{Zn} / \mathrm{Y}$ ratio, however, LPSO phases do not occur after TRC. In this alloy only icosahedral phases, which exhibit characteristics different from LPSO phases, can be found [27].

In this work, therefore, twin-roll casting of a Mg-Y-Zn magnesium alloy was applied to obtain thin sheets with a fine dendritic microstructure of $\alpha-\mathrm{Mg}$ and LPSO phases. The microstructure and texture of the twin-roll cast sheet was investigated. Furthermore, heat treatment was carried out after twin-roll casting in order to investigate the influence of different temperature and time regimes on the microstructure and the resulting texture. 


\section{Materials and Methods}

With a nominal composition of $\mathrm{Mg}-6.8 \mathrm{Y}-2.5 \mathrm{Zn}-0.4 \mathrm{Zr}(\mathrm{wt} \%)$, the magnesium alloy was processed in a twin-roll caster at an industrial scale (Institute of Metal Forming, Technische Universität Bergakademie Freiberg, Freiberg, Germany). The chemical composition of the alloy is summarized in Table 1. Ingots of WZ73 were melted in a steel crucible at $720^{\circ} \mathrm{C}$ under a protective gas atmosphere. The melt was transferred into a preheated casting system and twin-roll cast to sheets with a thickness of approximately $6 \mathrm{~mm}$. This condition is hereinafter referred to as the TRC state.

Table 1. Chemical composition of $\mathrm{Mg}-6.8 \mathrm{Y}-2.5 \mathrm{Zn}-0.4 \mathrm{Zr}$ (wt $\%)$ alloy determined via optical emission spectrometry (OES).

\begin{tabular}{ccccccccc}
\hline $\mathbf{Y}$ & $\mathbf{Z n}$ & $\mathbf{Z r}$ & $\mathbf{S i}$ & $\mathbf{F e}$ & $\mathbf{N i}$ & $\mathbf{C u}$ & Others & $\mathbf{M g}$ \\
\hline 6.8 & 2.5 & 0.4 & 0.01 & 0.005 & 0.001 & 0.001 & 0.01 & Balance \\
\hline
\end{tabular}

After twin-roll casting, heat treatment processes were carried out at temperatures ranging from $450^{\circ} \mathrm{C}$ to $525^{\circ} \mathrm{C}$ and at holding times of from $2 \mathrm{~h}$ to $24 \mathrm{~h}$. The samples were quenched in water directly after annealing in order to suppress the precipitation and recrystallization processes that occur during slow cooling.

Samples of the TRC and the annealed state were prepared by conventional grinding and polishing with an oxide suspension (OPS) for the characterization of the microstructure via optical and scanning electron microscopy (SEM, Stahlzentrum Freiberg e.V., Technische Universität Bergakademie Freiberg, Freiberg, Germany and the Institute of Materials Science, Technische Universtität Bergakademie Freiberg, Freiberg, Germany). All samples were taken as longitudinal specimens. A solution of ethanol, glacial acetic acid, picric acid and distilled water was used for etching. Energy dispersive X-ray spectroscopy (EDX) and X-ray diffraction (XRD) analysis were applied to measure the chemical composition of the individual constituents of the microstructure. XRD was performed on a Empyrean $\mathrm{Cu}$ LFF HR using CuK $\alpha$ radiation $(\lambda=1.540598 \AA$ ). Diffraction patterns were recorded within the $2 \Theta$-range of $5^{\circ}$ to $90^{\circ}$. The step size was chosen at $0.026^{\circ}$. Basis of identification is the ICSD database. Linear intercept method was applied for the measurement of the grain size. The volume fraction of the LPSO phase was determined by quantitative micrograph evaluation using the point counting procedure.

Texture analysis was performed by electron backscatter diffraction (EBSD) analysis using an FEI Versa 3D scanning electron microscope (Academic Center for Materials and Nanotechnology, University of Science and Technology, Krakow, Poland) equipped with a Hikari EBSD detector. The specimens were polished by an ion beam apparatus for $2 \mathrm{~h}$ with a voltage of $4 \mathrm{kV}$ and a beam current of $2 \mathrm{~mA}$. The voltage used for acquisition of the EBSD data were $15-20 \mathrm{kV}$ and the step size was $0.65 \mu \mathrm{m}$. All orientation maps were processed with EDAX/TSL OIM data collection software version 7 using a batch processing operation. The free MTEX MATLAB toolbox [28] was used for analysis of the EBSD data and the calculation of the pole figures of both the TRC and the annealed state.

\section{Results and Discussion}

\subsection{Microstructure of Twin-Roll Cast State}

Twin-roll casting of the WZ73 alloy led to the formation of a two-phase microstructure consisting of an $\alpha$-magnesium matrix, which was made up of dobulites with an average grain size of approximately $50 \mu \mathrm{m}$ and an LPSO phase, which formed network-like precipitates along the grain boundaries (Figure 1a). The volume fraction of the LPSO phase is $18 \%$. Locally differences occur due to the formation of segregations, especially in the mid-thickness of the strip, which are a result of the solidification characteristics during twin-roll casting. A characteristic microstructure normally develops during twin-roll casting of magnesium alloys, and typically consists of large columnar dendrites that grow from the surface edge to the mid-thickness of the strip: such a microstructure is reported, for 
example, for AZ31 [24,29,30] and ZAX210 [31]. In this case, however, such a microstructure was not observed. During twin-roll casting, solidification starts when the melt contacts the water-cooled rolls and propagates towards the mid-thickness of the TRC sheet. As solidification progresses, the residual melt is enriched with dissolved material from the solidification front and results in the formation of a centerline segregation, and the WZ73 magnesium alloy exhibited pronounced centerline segregation. The grain structure and morphology of the LPSO structures were more inhomogeneous at the center of the TRC sheet. An SEM micrograph (Figure 1b) revealed the dark gray magnesium matrix (A), which was surrounded by a network of block-shaped LPSO structures. Only small amounts of the alloying elements were dissolved within the magnesium matrix, with the lion's share precipitated in the LPSO structures- as can be seen from Figure 1c. White shining areas within the LPSO structures were enriched with Y. Similar results were achieved after conventional casting of the same ingots, as described in [32]. The important difference between the as-cast and the TRC state is that after conventional casting, fine lamellar structures could be observed within the magnesium matrix [18,33]. Lamellas of the LPSO structure within the Mg matrix did not occur after TRC. It was concluded, therefore, that the solidification kinetics of the twin-roll casting process influenced the precipitation kinetics of the LPSO phases. XRD results of the TRC state reveal that LPSO phase can be assigned to $18 \mathrm{R}$ or $14 \mathrm{H}$ structure (Figure 2 ), where preferably peaks of the $18 \mathrm{R}$ can be observed. A precise distinction between the two structures requires clarification by TEM investigations.
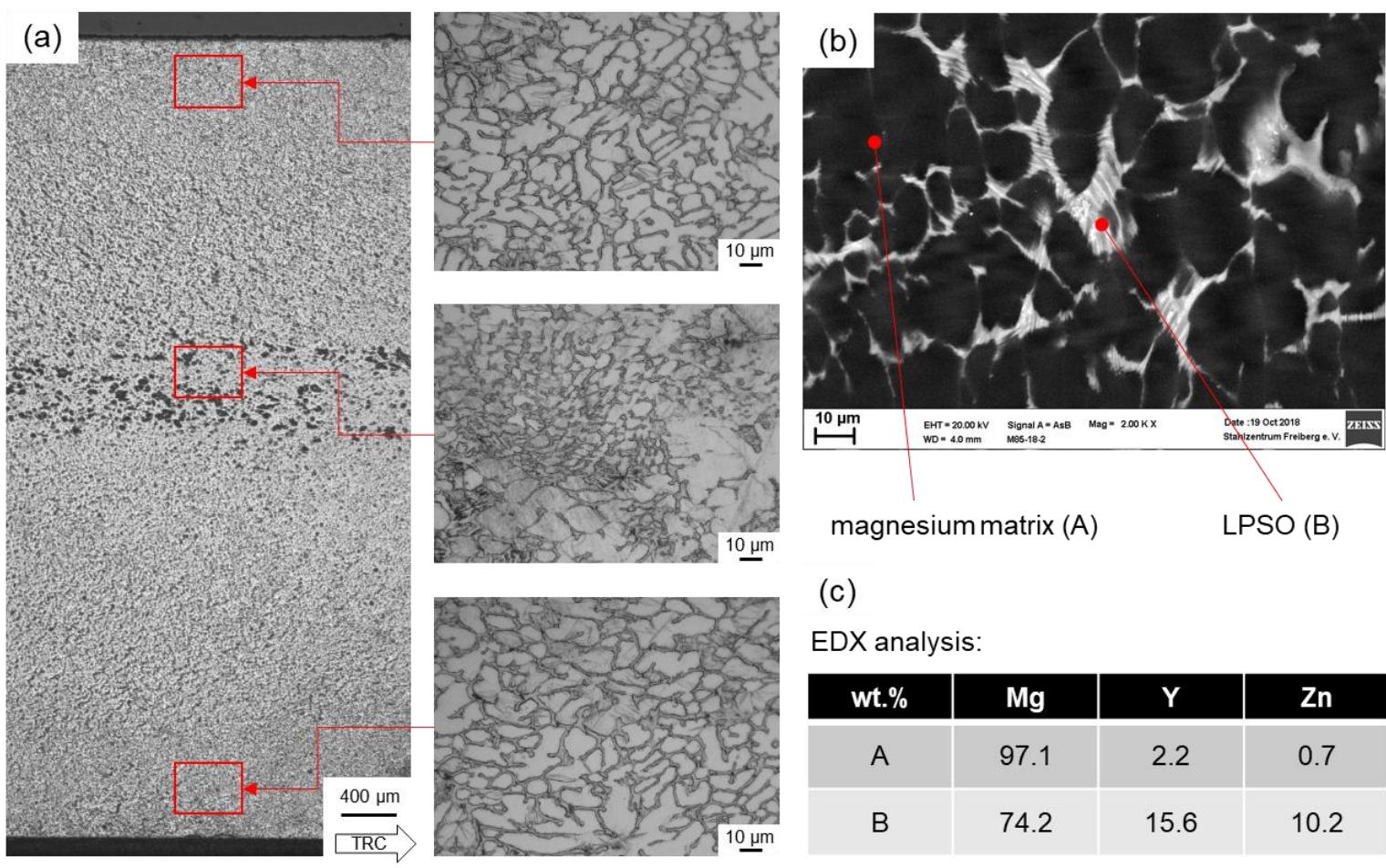

(c)

EDX analysis:

\begin{tabular}{|c|c|c|c|}
\hline wt.\% & Mg & $\mathbf{Y}$ & $\mathbf{Z n}$ \\
\hline A & 97.1 & 2.2 & 0.7 \\
\hline B & 74.2 & 15.6 & 10.2 \\
\hline
\end{tabular}

Figure 1. (a) Optical and (b) scanning electron microscopy (SEM) micrograph (at mid-thickness) of the microstructure of the twin-roll cast (TRC) state of the WZ73 magnesium alloy and (c) hemical composition of microstructural constituents (A-magnesium matrix, B-LPSO) determined by means of energy dispersive $\mathrm{X}$-ray spectroscopy (EDX)-analysis. 


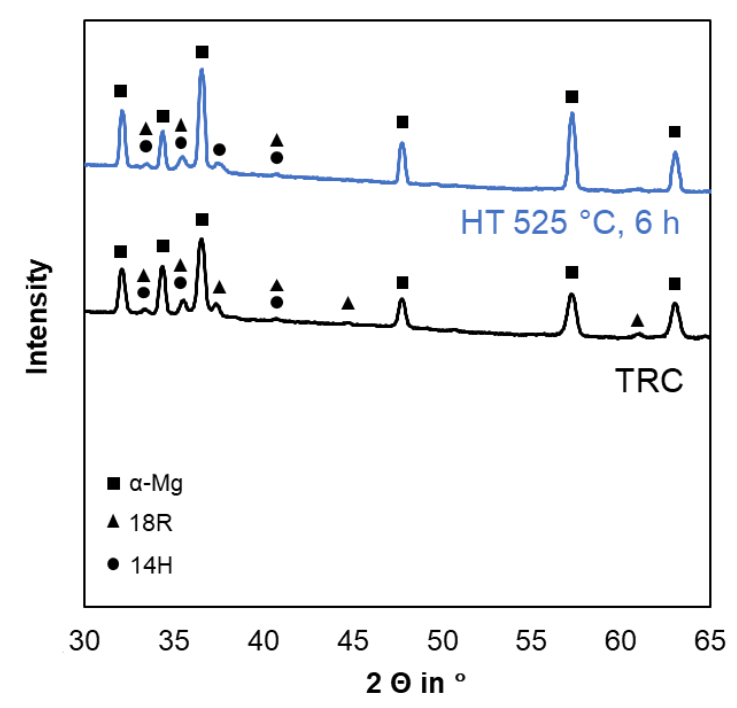

Figure 2. Results of the X-ray diffraction (XRD) analysis of the twin-roll cast (TRC) and the heat-treated (HT) state $\left(525^{\circ} \mathrm{C}, 6 \mathrm{~h}\right)$.

\subsection{Microstructure of Annealed State}

After twin-roll casting, the sheets of the WZ73 alloy were annealed at temperatures ranging from $450{ }^{\circ} \mathrm{C}$ to $525^{\circ} \mathrm{C}$ with holding times of $2 \mathrm{~h}, 6 \mathrm{~h}, 12 \mathrm{~h}$ and $24 \mathrm{~h}$. Figure 3 (the upper area of the strip cross section) and Figure 4 (the mid-thickness of the strip) show the micrographs of the twin-roll cast and annealed WZ73 sheets with regard to temperature and holding time. The microstructures of the top and bottom of the strip showed similar changes during heat treatment and are therefore described by means of micrographs from the upper area of the sheet cross section only. Annealing of the twin-roll cast WZ73 alloy under the conditions selected for this work led to partial dissolution of the LPSO structures. The continuous network of the LPSO structures diminished and grain boundaries of the magnesium matrix could be observed, with these microstructural changes becoming more distinctive with increasing temperature and/or holding time. In particular, when the annealing temperature was $500{ }^{\circ} \mathrm{C}$ or $525^{\circ} \mathrm{C}$ with a holding time of $24 \mathrm{~h}$, segmentation of the LPSO structures occurred and the morphology changed significantly from a block-like shape to a granular and rod-like shape (red arrows in Figure 3c,f). The volume fraction of the LPSO phase decreases with increasing temperature. For example, at $500{ }^{\circ} \mathrm{C}$ and for $2 \mathrm{~h}$ it is $17 \%$ at the edge and between $7 \%$ and $11 \%$ at the mid-thickness of the strip. An increase to $525^{\circ} \mathrm{C}$ and $6 \mathrm{~h}$ results in a decrease of the volume fraction to $14 \%$ at the edge and $6-8 \%$ at the mid-thickness of the strip. These results are similar to those of Hagihara et al. [5], who describe the microstructural evolution of the $\mathrm{Mg}_{97} \mathrm{Y}_{2} \mathrm{Zn}_{1}$ alloy after extrusion and annealing. Lu et al. [34] describe the significant effects of heat treatment on the morphology of an as-cast Mg95.3Zn2Y2.7 magnesium alloy. After annealing at $540{ }^{\circ} \mathrm{C}$ for $4 \mathrm{~h}$, the microstructure exhibits rod-shaped LPSO structures. The changes mentioned above occur in a similar manner throughout the entire microstructure. However, the network of the LPSO phase in the mid-thickness is not continuous at lower temperatures and with shorter holding times (Figure 4), resulting in more pronounced grain growth during heat treatment due to the diminishing pinning effect of the block-shaped LPSO structures [35]. The average cord length of the grains increased slightly from $29.6 \mu \mathrm{m}( \pm 11.3 \mu \mathrm{m})$ after annealing at $500{ }^{\circ} \mathrm{C}$ and $2 \mathrm{~h}$ to $34.9 \mu \mathrm{m}( \pm 11.0 \mu \mathrm{m})$ after $500{ }^{\circ} \mathrm{C}$ and $24 \mathrm{~h}$. Annealing at $525^{\circ} \mathrm{C}$ and $6 \mathrm{~h}$ resulted in an average cord length of $41.7 \mu \mathrm{m}( \pm 11.0 \mu \mathrm{m})$. 

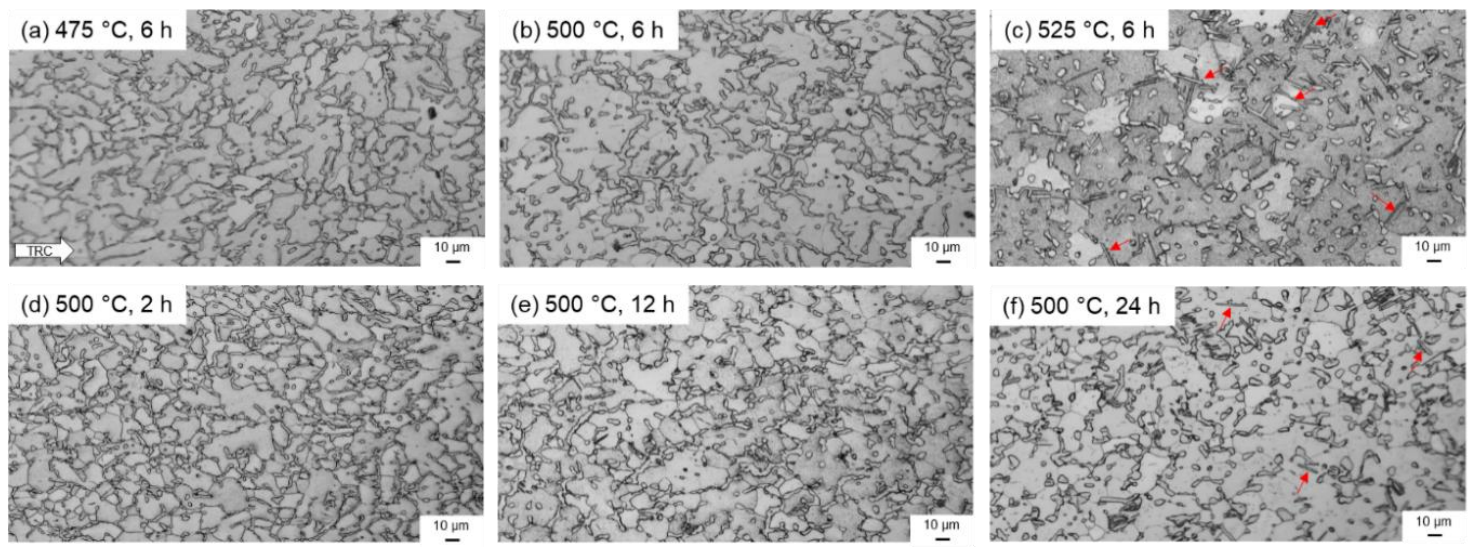

Figure 3. Optical micrographs of the WZ73 TRC sheets after annealing at different temperatures and holding times, with the comparison exemplified by the microstructure from the upper area of the strip cross section (red arrows: LPSO phase with a rod-like shape): (a) $475^{\circ} \mathrm{C}, 6 \mathrm{~h},(\mathbf{b}) 500{ }^{\circ} \mathrm{C}, 6 \mathrm{~h},(\mathbf{c}) 525^{\circ} \mathrm{C}$, $6 \mathrm{~h},(\mathrm{~d}) 500^{\circ} \mathrm{C}, 2 \mathrm{~h},(\mathbf{e}) 500{ }^{\circ} \mathrm{C}, 12 \mathrm{~h}$ and (f) $500{ }^{\circ} \mathrm{C}, 24 \mathrm{~h}$.
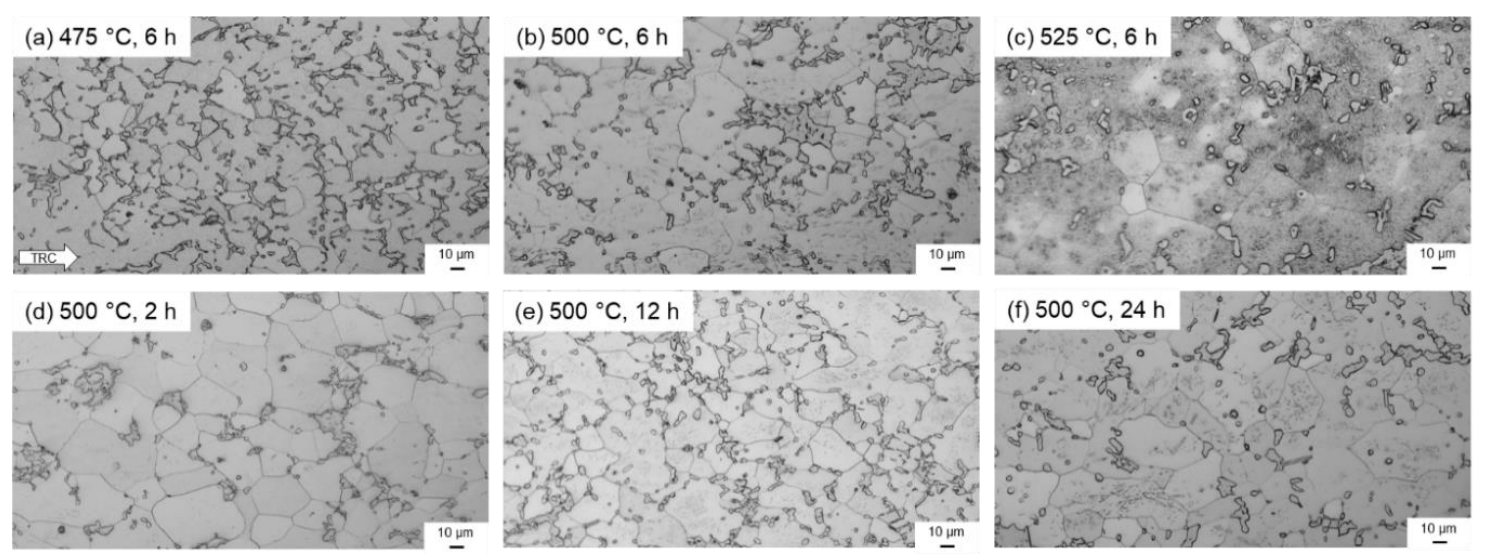

Figure 4. Optical micrographs of the WZ73 TRC sheets after annealing at different temperatures and holding times, in the mid-thickness of the sheet: (a) $475^{\circ} \mathrm{C}, 6 \mathrm{~h},(\mathrm{~b}) 500{ }^{\circ} \mathrm{C}, 6 \mathrm{~h},(\mathrm{c}) 525^{\circ} \mathrm{C}, 6 \mathrm{~h},(\mathrm{~d}) 500{ }^{\circ} \mathrm{C}$, $2 \mathrm{~h},(\mathbf{e}) 500{ }^{\circ} \mathrm{C}, 12 \mathrm{~h}$ and (f) $500{ }^{\circ} \mathrm{C}, 24 \mathrm{~h}$.

The change of the shape of the LPSO structure can be better visualized by using SEM micrographs (Figure 5). The segmentation of the LPSO structures occurred with increased annealing temperatures of from $500{ }^{\circ} \mathrm{C}$ to $525^{\circ} \mathrm{C}$ and at holding times of from $2 \mathrm{~h}$ to $6 \mathrm{~h}$. The size of the rod-shaped LPSO structures was about $1 \mu \mathrm{m}$ to $2 \mu \mathrm{m}$ in thickness and $8 \mu \mathrm{m}$ to $12 \mu \mathrm{m}$ in length. The rod-shaped phases were distributed with a random orientation. The chemical composition of the LPSO structure remained unchanged during heat treatment and was about $15 \mathrm{wt} \%$ to $18 \mathrm{wt} \%$ for $\mathrm{Y}$ and $8 \mathrm{wt} \%$ to $11 \mathrm{wt} \%$ for $\mathrm{Zn}$ over the entire cross section. Tiny, cubic particles (white) mainly consisted of $\mathrm{Y}$ and seemed to be residuals from the ingot production process. The dissolution of the network-shaped LPSO structures led to an increased amount of $Y$ and $\mathrm{Zn}$ within the magnesium matrix with increasing annealing temperature (Figure $5 c$ ). With longer holding times at constant temperature, the atoms of the alloying elements no longer dissolved into the matrix, as the maximum solubility of $\mathrm{Y}$ and $\mathrm{Zn}$ in magnesium solid solution is a time-independent process. Due to their lower solubility at room temperature, $\mathrm{Y}$ and $\mathrm{Zn}$ precipitate as soon as the temperature falls below the solidus temperature during cooling. After annealing, the samples were quenched in water. Therefore, precipitation processes were suppressed by the rapid cooling rate. 

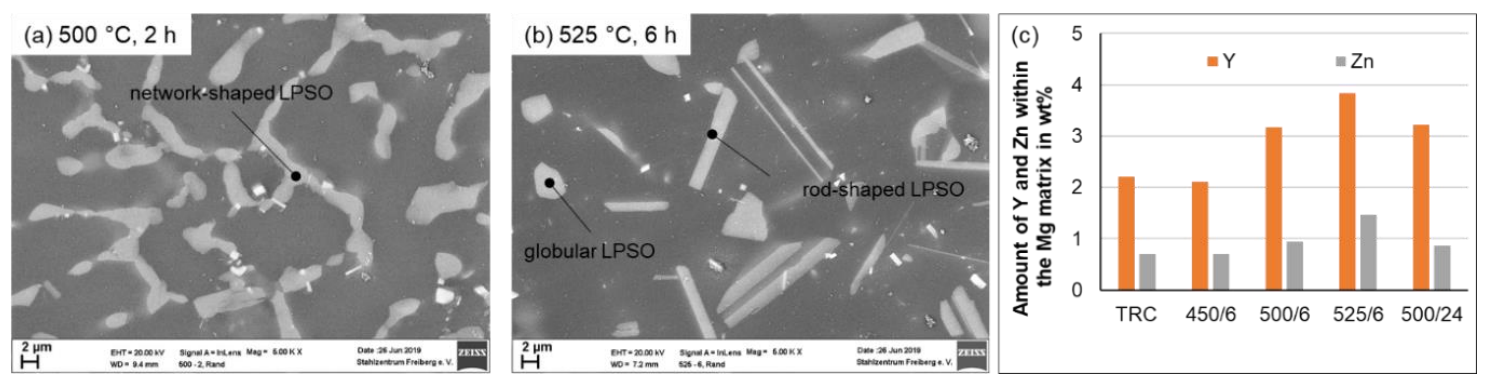

Figure 5. SEM micrographs of the twin-roll cast and annealed WZ73 alloy at (a) $500{ }^{\circ} \mathrm{C}, 2 \mathrm{~h},(\mathbf{b}) 525{ }^{\circ} \mathrm{C}$, $6 \mathrm{~h}$ and (c) the amount of $\mathrm{Y}$ and $\mathrm{Zn}$ within the magnesium matrix (mid-thickness of the strip) for different conditions: TRC and after annealing at ${ }^{\circ} \mathrm{C} / \mathrm{h}$.

Annealing at $500^{\circ} \mathrm{C}$ for $6 \mathrm{~h}$ compared to at $525^{\circ} \mathrm{C}$ for $6 \mathrm{~h}$ and a low cooling rate (in air) exhibited different precipitation kinetics as a function of the dissolved quantities of $\mathrm{Y}$ and $\mathrm{Zn}$ in the magnesium matrix (Figure 6). After heat treatment at $525^{\circ} \mathrm{C}$, fine lamellar LPSO structures precipitated within the grains of the magnesium matrix. XRD results indicate that the transformation from the $18 \mathrm{R}$ to the $14 \mathrm{H}$ phase has occurred, as described in Liu et al. [21]. These lamellae are known from microstructures of LPSO-containing magnesium alloys after conventional casting $[18,33]$. It was therefore assumed that annealing at high temperatures resulted in the dissolution of the network-shaped LPSO phase during the holding time. Cooling at a low cooling rate then led to the formation of the fine lamellae of an LPSO structure-which could be assigned to the $14 \mathrm{H}$ phase [36].
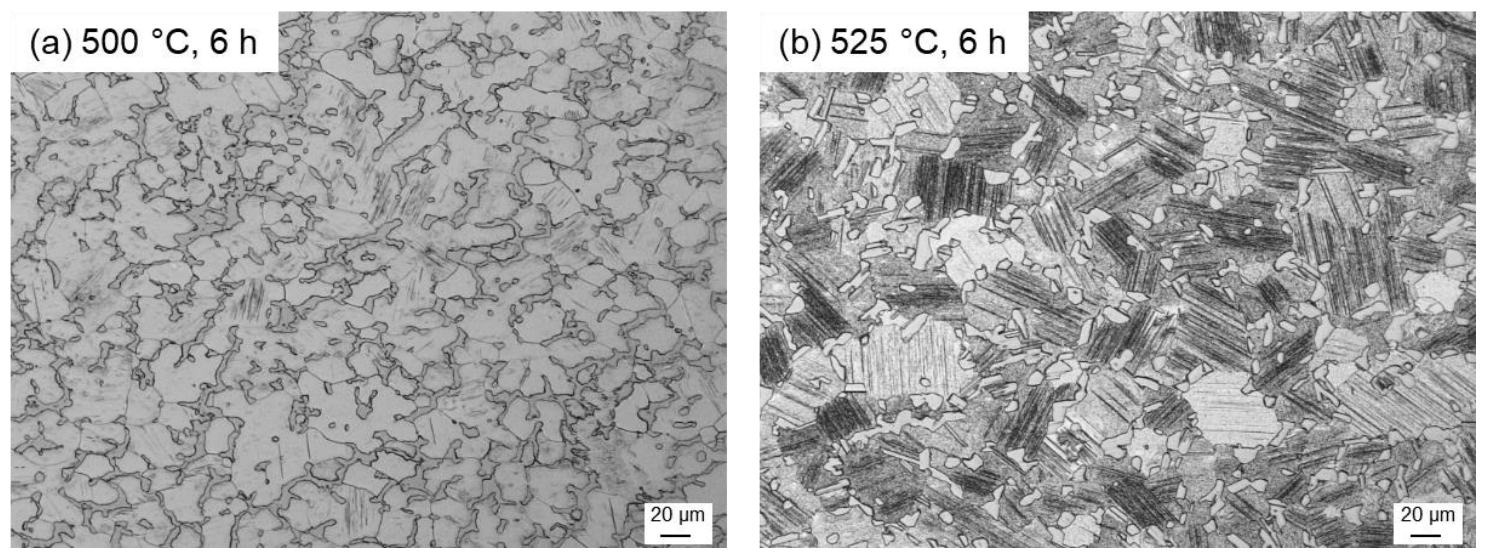

Figure 6. Optical micrographs of the twin-roll cast and annealed WZ73 alloy at (a) $500{ }^{\circ} \mathrm{C}, 6 \mathrm{~h}$ and

(b) $525{ }^{\circ} \mathrm{C}, 6 \mathrm{~h}$ after cooling in air (upper area of the strip cross section).

\subsection{Texture Evolution}

Figure 7 shows the (0001) and (1010) pole figures taken from the mid-thickness of the strip and the misorientation angle distribution for the twin-roll cast and the annealed conditions. In the TRC strip, the (0001) pole figure exhibited a basal texture, as most of the crystals were oriented with their basal planes parallel to the sheet plane. However, both exhibited a low maximum intensity. During twin-roll casting, two kinds of textures typically arise: a deformation texture (due to the rolling process during TRC) or a casting texture (due to the directional growth of columnar grains). The WZ73 magnesium alloy did not offer the characteristic dendritic microstructure typified by columnar grains growing toward the center of the strip, as reported for other magnesium alloys [37]. Therefore, it was assumed that the texture after twin-roll casting resulted from the low degree of deformation during the rolling process. 


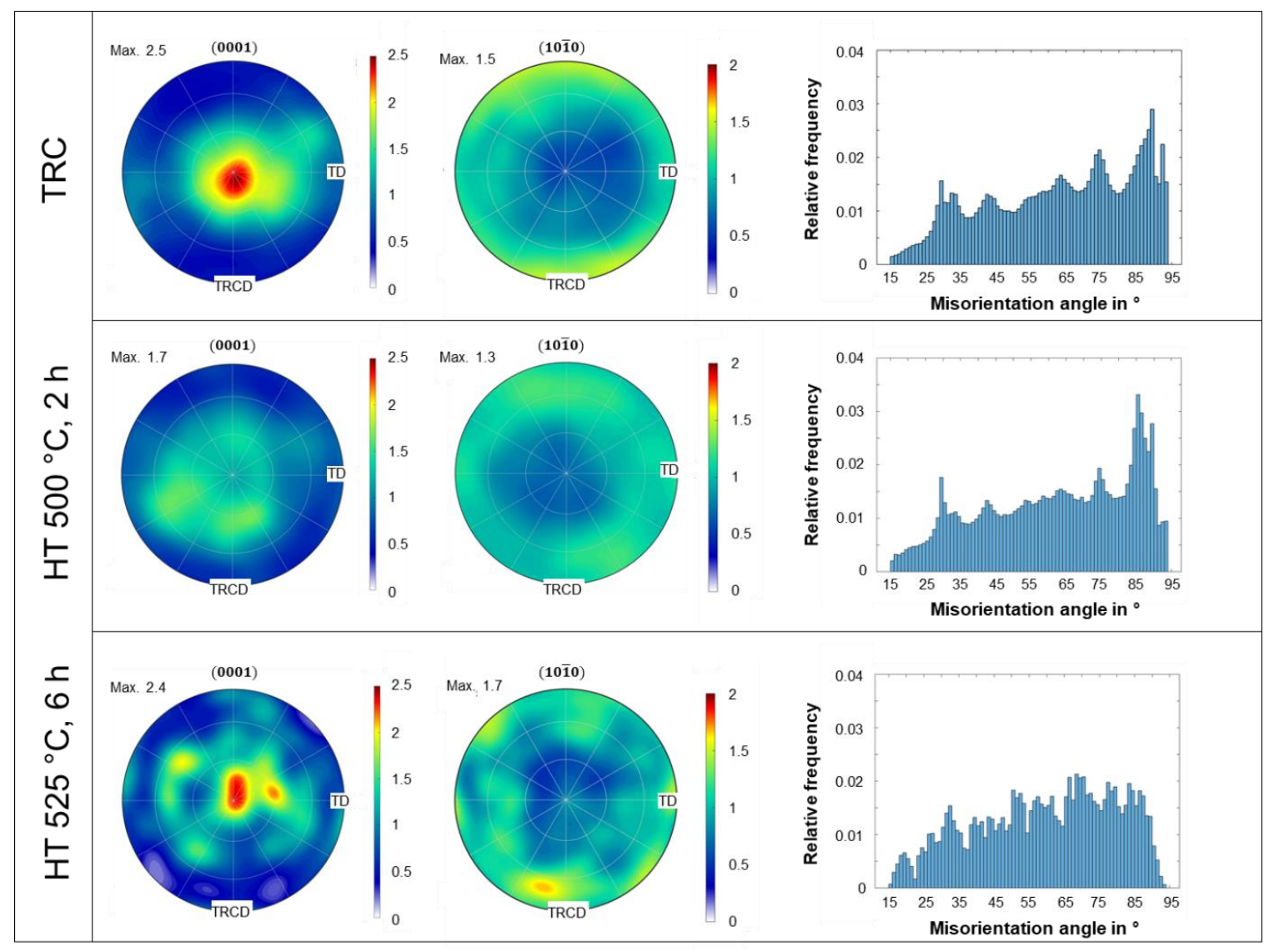

Figure 7. (0001) and (1010) pole figures and misorientation angle distribution of the twin-roll cast and the heat-treated conditions.

Heat treatment at $500{ }^{\circ} \mathrm{C}$ for $2 \mathrm{~h}$ led to texture weakening. The maximal pole intensity was separated into several basal poles, which were aligned away from the core intensity. An angular distribution of the basal planes in the TRC direction (TRCD) as well as in the transverse direction (TD) could be observed. Random textures in LPSO-containing alloys after homogenization treatment are also reported in [35]. Increasing annealing temperature and holding time resulted in slightly higher texture intensity. A basal texture developed with a maximum core intensity. Several texture components arose, however, resulting in broadening of the basal pole in the TRCD and in the TD.

The misorientation angle distributions of the TRC and the HT $500{ }^{\circ} \mathrm{C}, 2 \mathrm{~h}$ states revealed misorientations that could be assigned to different types of twins, such as tension, compression or double twins (Figure 7). It was assumed that the detected twins were not preparation twins, because ion polishing was applied in sample preparation and is known to keep the introduction of deformations into the sample surface low. Here, the largest peak at misorientation angles between $85^{\circ}$ and $90^{\circ}$ could be attributed to the occurrence of $\{10 \overline{1} 2\}$-tension twins. This type of twinning often occurs during the deformation of magnesium alloys and can be activated even at low strains due to the low critical resolved shear stress (CRSS). Other characteristic maxima in the misorientation angle distribution arose between $35^{\circ}$ and $45^{\circ}$ as well as at $56^{\circ}$ and at $64^{\circ}$. These could be assigned to secondary twinning $(\{10 \overline{1} 1\}\{10 \overline{1} 2\}$ - and $\{10 \overline{1} 3\}\{10 \overline{1} 2\}$-double twins) and $\{10 \overline{1} 1\}$-or $\{10 \overline{1} 3\}$-compression twins. In addition, two further maximum peaks could be recorded. The higher relative frequency for grain boundaries with misorientation angles of $30^{\circ}$ is characteristic for magnesium sheets with basal texture [38]. Grain boundaries with misorientation angles between $70^{\circ}$ and $80^{\circ}$ are misoriented around the $\langle 1120\rangle$-axis and, according to Chun and Davies [39], are derived from $\{10 \overline{1} 2\}$-tension twins in deformation bands. In the twin-roll cast sheets of the WZ73 alloy, twin bands could not be 
observed. However, twins were visible in several adjacent grains of the magnesium matrix (Figure 8). These accumulated twins could have been the origin for misorientation angles of between $70^{\circ}$ and $80^{\circ}$.

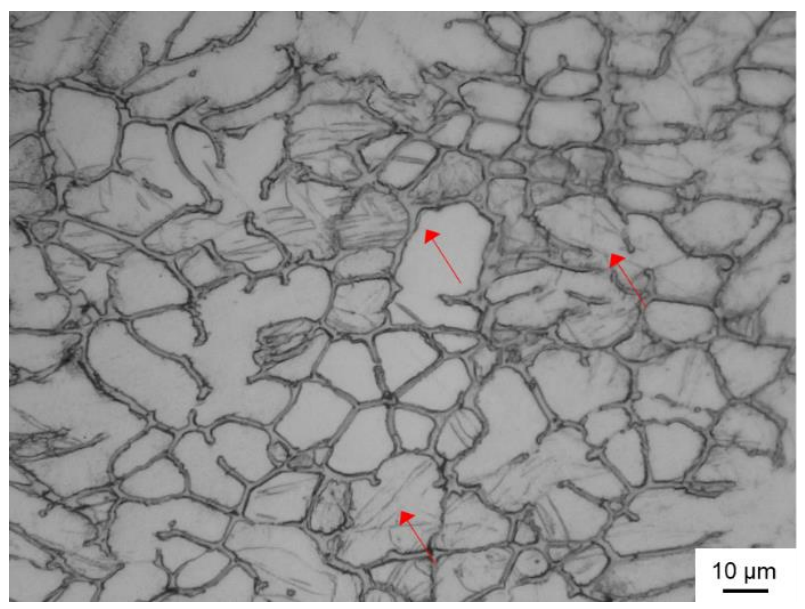

Figure 8. Optical micrograph of the WZ73 alloy in the twin-roll cast condition revealing twins in several adjacent grains of the magnesium matrix (red arrows).

After heat treatment at $525{ }^{\circ} \mathrm{C}$ for $6 \mathrm{~h}$, the misorientation angle distribution revealed a uniform distribution of high-angle grain boundaries $\left(>15^{\circ}\right)$. It was assumed that due to static recrystallization, sub-grain formation occurred first before the subsequent migration of sub-grain boundaries. These low-angle grain boundaries were further transformed into high-angle grain boundaries-as described by Wang et al. [40] during twin-roll casting and annealing of a ZK60 magnesium alloy.

In future investigations, the microstructure and texture evolution as a function of the TRC parameters will be the main focus. For example, the strain can be increased by changing the casting speed or the roll gap. The question is to be investigated whether this significantly increases the proportion of twins and promotes the occurrence of twin-induced dynamic recrystallization (TDRX) during TRC and/or the recrystallization at twin boundaries during subsequent heat treatment. Both are known for generating random textures.

\section{Conclusions}

In this work, twin-roll casting of the WZ73 magnesium alloy was adopted to obtain thin sheets with a fine dendritic microstructure of $\alpha-\mathrm{Mg}$ and LPSO phases. Evolution of both the microstructure and texture was determined during heat treatment of the twin-roll cast sheet. The main conclusions are summarized as follows:

1. Twin-roll casting of the WZ73 alloy led to the formation of a two-phase microstructure consisting of an $\alpha$-magnesium matrix and the LPSO phase, which was located as a network-like phase along the grain boundaries of the matrix grains. The characteristic microstructure of columnar dendrites growing from the surface edge to the mid-thickness of the TRC strips-which typically develops during twin-roll casting of magnesium alloys and was reported for AZ31 and ZAX210—was not observed;

2. The most important difference between the as-cast (reported in the literature) and the TRC state is that after conventional casting, fine lamellar structures could be observed within the magnesium matrix. Lamellae of the LPSO structure within the Mg matrix did not occur after TRC;

3. Annealing of the twin-roll cast WZ73 alloy led to partial dissolution of the LPSO structures into the matrix. The continuous network of the LPSO structures diminished and the grain boundaries of the magnesium matrix could be observed. Annealing temperatures of $500^{\circ} \mathrm{C}$ or $525^{\circ} \mathrm{C}$ with a 
holding time of $24 \mathrm{~h}$ resulted in the segmentation of the LPSO structures, with the morphology changing significantly from block-shaped to a globular and rod-like shape;

4. After heat treatment at $525^{\circ} \mathrm{C}$, fine lamellar LPSO structures precipitated within the grains of the magnesium matrix. Those lamellae are known from microstructures of LPSO-containing magnesium alloys after conventional casting. It was therefore assumed that annealing at high temperatures resulted in the dissolution of the network-shaped LPSO phase during the holding time and led to the formation of fine lamellae of LPSO structures within the magnesium matrix, which could be assigned to the $14 \mathrm{H}$ phase;

5. In the TRC strip, the (0001) pole figure exhibited a basal texture character, because most of the crystals were oriented with their basal planes parallel to the sheet plane. However, the maximum intensity was low. Heat treatment at $500{ }^{\circ} \mathrm{C}$ for two hours led to weakening of the texture. The maximal pole intensity was separated into several basal poles, which were aligned away from the core intensity. Angular distribution of the basal planes in the TRC direction as well as in the TD could also be observed.

Author Contributions: Conceptualization, K.K. and M.U.; methodology, K.K.; formal analysis, M.U.; investigation, K.K. and F.A.; resources, U.P.; data curation, M.U.; writing-original draft preparation, K.K.; writing-review and editing, M.U., F.A. and U.P.; visualization, K.K. and M.U.; supervision, U.P.; project administration, R.K.; funding acquisition, R.K. All authors have read and agreed to the published version of the manuscript.

Funding: The research was carried out within the framework of the AMARETO project. The "Saxon Alliance for Material and Resource Efficient Technologies" (AMARETO) is funded by the European Union (European Regional Development Fund) and the Free State of Saxony.
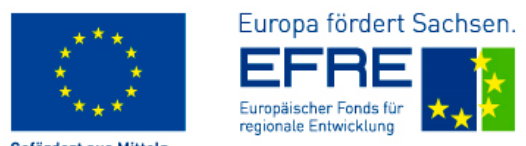

Gefördert aus Mittel

Acknowledgments: This research was supported by the Stahlzentrum Freiberg e.V., Technische Universität Bergakademie Freiberg, Germany and Institute of Materials Science, Technische Universtität Bergakademie Freiberg, Germany. We thank the Academic Center for Materials and Nanotechnology, University of Science and Technology, Krakow, Poland for EBSD and XRD analysis.

Conflicts of Interest: The authors declare no conflicts of interest. The funders had no role in the design of the study; in the collection, analyses or interpretation of data; in the writing of the manuscript or in the decision to publish the results.

\section{References}

1. Wan, Y.; Liu, C.; Xiao, H.; Gao, Y.; Jiang, S.; Chen, Z. Improving the Ductility of Mg-Gd-Y-Zr Alloy through Extrusion and a Following Rolling. Adv. Eng. Mater. 2018, 20, 1701041. [CrossRef]

2. Shao, X.H.; Yang, Z.Q.; Ma, X.L. Strengthening and toughening mechanisms in Mg-Zn-Y alloy with a long period stacking ordered structure. Acta Mater. 2010, 58, 4760-4771. [CrossRef]

3. Li, Y.X.; Zhu, G.; Qiu, D.; Yin, D.D.; Rong, Y.H.; Zhang, M.-X. The intrinsic effect of long period stacking ordered phases on mechanical properties in Mg-RE based alloys. J. Alloys Compd. 2016, 660, 252-257. [CrossRef]

4. Kishida, K.; Nagai, K.; Matsumoto, A.; Yasuhara, A.; Inui, H. Crystal structures of highly-ordered long-period stacking-ordered phases with $18 \mathrm{R}, 14 \mathrm{H}$ and $10 \mathrm{H}$-type stacking sequences in the Mg-Zn-Y system. Acta Mater. 2015, 99, 228-239. [CrossRef]

5. Hagihara, K.; Kinoshita, A.; Sugino, Y.; Yamasaki, M.; Kawamura, Y.; Yasuda, H.Y.; Umakoshi, Y. Effect of long-period stacking ordered phase on mechanical properties of Mg97Zn1Y2 extruded alloy. Acta Mater. 2010, 58, 6282-6893. [CrossRef]

6. Liu, H.; Xue, F.; Bai, J.; Sun, Y. Effect of heat treatments on the microstructure and mechanical properties of an extruded Mg95.5Y3Zn1.5 alloy. Mater. Sci. Eng. A 2013, 585, 261-267. [CrossRef] 
7. Kim, K.-H.; Lee, J.G.; Bae, G.T.; Bae, J.H.; Kim, N.J. Mechanical Properties and Microstructure of Twin-Roll Cast Mg-Zn-Y Alloy. Mater. Trans. 2008, 49, 980-985. [CrossRef]

8. Li, R.G.; Fang, D.Q.; An, J.; Lu, Y.; Cao, Z.Y.; Liu, Y.B. Comparative studies on the microstructure evolution and fracture behavior between hot-rolled and as-cast Mg96ZnY3 alloys. Mater. Charact. 2009, 60, 470-475. [CrossRef]

9. Wang, B.S.; Xiong, S.; Liu, Y. Tensile fracture of as-cast and hot rolled Mg-Zn-Y alloy with long-period stacking phase. Trans. Nonferr. Met. Soc. 2010, 20, s488-s492. [CrossRef]

10. Suzawa, K.; Inoue, S.I.; Nishimoto, S.; Fuchigami, S.; Yamasaki, M.; Kawamura, Y.; Yoshida, K.; Kawabe, N. High-strain-rate superplasticity and tensile behavior of fine-grained Mg97Zn1Y2 alloys fabricated by chip/ribbon-consolidation. Mater. Sci. Eng. A 2019, 764, 138179. [CrossRef]

11. Zhu, Y.M.; Morton, A.J.; Nie, J.F. The $18 \mathrm{R}$ and $14 \mathrm{H}$ long-period stacking ordered structures in Mg-Y-Zn alloys. Acta Mater. 2010, 58, 2936-2947. [CrossRef]

12. Zhu, Y. Microstructural Characterization of Mg-Y-Zn Based Alloys. Ph.D. Thesis, Monash University, Melbourne, Australia, 2011.

13. Kim, J.K.; Sandlöbes, S.; Raabe, D. On the room temperature deformation mechanisms of a Mg-Y-Zn alloy with long-period-stacking-ordered structures. Acta Mater. 2015, 82, 414-423. [CrossRef]

14. Itoi, T.; Inazawa, T.; Yamasaki, M.; Kawamura, Y.; Hirohashi, M. Microstructure and mechanical properties of Mg-Zn-Y alloy sheet prepared by hot-rolling. Mater. Sci. Eng. A 2013, 560, 216-223. [CrossRef]

15. Frank, F.C.; Stroh, A.N. On the theory of kinking. Proc. Phys. Soc. Sect. B 1952, 65, 811-821. [CrossRef]

16. Ashby, M.F.; Gelles, S.H.; Tanner, L.E. The stress at which dislocations are generated at a particle-matrix interface. Philos. Mag. 1969, 19, 757-771. [CrossRef]

17. Yamasaki, M.; Hashimoto, K.; Hagihara, K.; Kawamura, Y. Effect of multimodal microstructure evolution on mechanical properties of Mg-Zn-Y extruded alloy. Acta Mater. 2011, 59, 3646-3658. [CrossRef]

18. Shi, B.; Chen, R.; Ke, W. Effects of processing route on texture and mechanical properties of WZ62 alloy. Trans. Nonferrous Met. Soc. China 2011, 21, 830-835. [CrossRef]

19. Xu, D.; Han, E.; Xu, Y.B. Effect of long-period stacking ordered phase on microstructure, mechanical property and corrosion resistance of Mg alloys: A review. Prog. Nat. Sci. Mater. Int. 2016, 26, 117-128. [CrossRef]

20. Lv, B.-J.; Peng, J.; Zhu, L.-L.; Wang, Y.-J.; Tang, A.-T. The effect of 14 H LPSO phase on dynamic recrystallization behavior and hot workability of Mg-2.0Zn-0.3Zr-5.8Y alloy. Mater. Sci. Eng. A 2014, 599, 150-159. [CrossRef]

21. Liu, H.; Huang, H.; Wang, C.; Sun, J.; Bai, J.; Xue, F.; Ma, A.; Chen, X.B. Recent Advances in LPSO-Containing Wrought Magnesium Alloys: Relationships Between Processing, Microstructure, and Mechanical Properties. JOM 2019, 71, 3314-3327. [CrossRef]

22. Liu, J.B.; Zhang, K.; Han, J.T.; Li, X.G.; Li, Y.J.; Ma, M.L.; Yuan, J.W.; Shi, G.L. Microstructure and texture evolution of Mg-7Y-1Nd-0.5Zr alloy sheets with different rolling temperatures. Rare Met. 2016, 14, 16. [CrossRef]

23. Dai, S.; Wang, F.; Wang, Z.; Liu, Z.; Mao, P. Microstructure, mechanical properties, and texture evolution of $\mathrm{Mg}-\mathrm{Zn}-\mathrm{Y}-\mathrm{Zr}$ alloy fabricated by hot extrusion-shearing process. J. Mater. Sci. 2020, 55, 375-388. [CrossRef]

24. Neh, K.; Ullmann, M.; Oswald, M.; Berge, F.; Kawalla, R. Twin roll casting and strip rolling of several magnesium alloys. Mater. Today Proc. 2015, 2, 45-52. [CrossRef]

25. Kawalla, R.; Ullmann, M.; Schmidt, C.; Dembińska, J.; Vogt, H.-P. Properties of Magnesium Strips produced by Twin-Roll-Casting and Hot Rolling. In Materials Science Forum 690; Trans Tech Publications Ltd.: Stafa-Zurich, Switzerland, 2011; pp. 21-24.

26. Kawalla, R.; Ullmann, M.; Oswald, M.; Vogt, H.-P. Developement of a strop rolling technology for Mg alloys based on the twin roll casting process. Magnes. Technol. 2008, 177, 182.

27. Gröbner, J.; Kozlov, A.; Fang, X.Y.; Geng, J.; Nie, J.F.; Schmid-Fetzer, R. Phase equilibria and transformations in ternary Mg-rich Mg-Y-Zn alloys. Acta Mater. 2012, 60, 5948-5962. [CrossRef]

28. Bachmann, F.; Hielscher, R.; Schaeben, H. Texture Analysis with MTEX-Free and Open Source Software Toolbox. Solid State Phenom. 2010, 160, 63-68. [CrossRef]

29. Ullmann, M. Rekristallisationsverhalten von Geglühtem AZ31-Gießwalzband Beim Warmwalzen. Ph.D. Thesis, Technische Universität Bergakademie Freiberg, Freiberg, Germany, 2014.

30. Hadadzadeh, A.; Wells, M.A. Inverse and centreline segregation formation in twin roll cast AZ31 magnesium alloy. Mater. Sci. Technol. 2015, 31, 1715-1726. [CrossRef] 
31. Kittner, K.; Ullmann, M.; Henseler, T.; Kawalla, R.; Prahl, U. Microstructure and Hot Deformation Behavior of Twin Roll Cast Mg-2Zn-1Al-0.3Ca Alloy. Materials 2019, 12, 1020. [CrossRef]

32. Ullmann, M.; Schmidtchen, M.; Kittner, K.; Henseler, T.; Kawalla, R.; Prahl, U. Hot Deformation Behaviour and Processing Maps of an as-Cast Mg-6.8Y-2.5Zn-0.4Zr Alloy. Mater. Sci. Forum 2019, 949, 57-65. [CrossRef]

33. Neh, K.; Ullmann, M.; Kawalla, R. Mechanical Properties and Microstructure of the Magnesium Alloy Mg-6.8Y-2.5Zn-0.5Al Produced by Casting and Hot Rolling. Mater. Sci. Forum 2018, 918, 3-12. [CrossRef]

34. Lu, R.; Wang, J.; Chen, Y.; Qin, D.; Yang, W.; Wu, Z. Effects of heat treatment on the morphology of long-period stacking ordered phase, the corresponding damping capacities and mechanical properties of $\mathrm{Mg}-\mathrm{Zn}-\mathrm{Y}$ alloys. J. Alloys Compd. 2015, 639, 541-546. [CrossRef]

35. Xu, C.; Nakata, T.; Qiao, X.; Zheng, M.; Wu, K.; Kamado, S. Effect of LPSO and SFs on microstructure evolution and mechanical properties of Mg-Gd-Y-Zn-Zr alloy. Sci. Rep. 2017, 7, 40846. [CrossRef] [PubMed]

36. Wu, Y.J.; Zeng, X.Q.; Lin, D.L.; Peng, L.M.; Ding, W.J. The microstructure evolution with lamellar 14H-type LPSO structure in an Mg96.5Gd2.5Zn1 alloy during solid solution heat treatment at 773 K. J. Alloys Compd. 2009, 477, 193-197. [CrossRef]

37. Kittner, K.; Ullman, M.; Henseler, T.; Prahl, U.; Kawalla, R. Dynamic recrystallization behavior of twin roll cast ZAX210 strips during hot deformation. In Proceedings of the Conference METAL 2019, Brno, Czech Republic, 22-24 May 2019.

38. Tong, L.B.; Zheng, M.Y.; Cheng, L.R.; Zhang, D.P.; Kamado, S.; Meng, J.; Zhang, H.J. Influence of deformation rate on microstructure, texture and mechanical properties of indirect-extruded $\mathrm{Mg}-\mathrm{Zn}-\mathrm{Ca}$ alloy. Mater. Charact. 2015, 104, 66-72. [CrossRef]

39. Chun, Y.B.; Davies, C.H.J. The evolution of in-grain misorientation axes (IGMA) during deformation of wrought magnesium alloy AZ31. In Magnesium Technology, Proceedings of the TMS 2010 Annual Meeting and Exhibition, Seattle, WA, USA, 14-18 February 2010; TMS (The Minerals, Metals \& Materials Society): Warrendale, PA, USA, 2010; pp. 345-349.

40. Wang, Y.; Wang, S.R.; Ma, R.; Yang, L.Y. Static Recrystallization of Magnesium Alloy during TRC-HC Deformation Followed by Annealing. In Advanced Materials Research; Trans Tech Publications Ltd.: Stafa-Zurich, Switzerland, 2011; Volume 295, pp. 730-733. [CrossRef] 